\title{
Plutarco e a leitura alegórica dos hieróglifos
}

\author{
EMANUEL ARAÚJO \\ Universidade de Brasília \\ Departamento de História
}

\begin{abstract}
RESUMO: Até a verdadeira tradução dos hieróglifos por Champollion (1822), fazia-se normalmente uma interpretação alegórica desses signos. No caso de Plutarco e de muitos outros autores, tratava-se na verdade de uma interpretatio graeca do Egito. Observa-se isso claramente na composição de Sobre Ísis e Osíris, onde se verifica a manipulação daquela escrita por intermédio de interpretações etimológicas não raro equivocadas, aqui examinadas à luz do instrumental egiptológico.
\end{abstract}

PALAVRAS-CHAVE: Plutarco; hieróglifos; Sobre isis e Osíris; mitologia egípcia.

Um dos livros mais célebres de Plutarco - e, portanto, dos mais estudados - é Sobre Ísis e Osíris, que ocupa as seções 351 C-384 C, com oitenta capítulos, de suas Obras morais (para sua tradução utilizei as edições de Hopfner, 1940-1941; Babbitt, 1969; Griffiths, 1970; e Froidefond, 1988). Demasiado conhecido, não cabe aqui resumir seu conteúdo, mas sempre é oportuno lembrar a importância que lhe é reconhecida pelos egiptólogos: afinal, como nota Vandier (Vandier, 1949, p. 51), "é em Plutarco que a lenda de Osíris nos foi conservada em sua forma mais completa, se não a mais pura”. Todavia, convém assinalar que não temos aí uma pesquisa de fontes em primeira mão, e sim a interpretatio graeca de uma cultura estranha, de uma religião estranha, de um povo estranho. Mas era um mundo que fascinava os estrangeiros, um mundo de história três vezes milenar que encerrava e guardava, supunha-se, o segredo de uma sapiência também milenar. Nessa época os próprios intelectuais egípcios, refinados e helenizados, já viviam um pouco da nostalgia desse passado pujante e um tanto 'reinventado'. Os deuses pareciam deixar a humanidade, desinteressados de sua criação, mas sobretudo expulsos pela filosofia grega, pelas novas concepções cosmológicas e metafísicas tão distantes da concretitude dos mitos.

Ainda que num contexto desfavorável, a velha religião egípcia se recusava a morrer, ganhando sobrevida justamente no interesse que despertava entre pensadores e escritores dessa koinê tão vigorosa em sua unidade intelectual. As culturas jovens, ainda que pensassem o mundo de forma diferente e até incompatível com o sistema de representações do homem da época faraônica, tentavam atualizar o que não entendiam direito, "modernizando' aquilo que julgavam compreender, mas de qualquer modo sob a convicção de que a origem de toda a sabedoria jazia no vale do Nilo. O sentimento a esse respeito do homem culto médio do final da Antigüidade está bem expresso por Amiano Marcelino (22, 16), no século IV d.C.: 
Se alguém deseja investigar com mente atenta as muitas publicações sobre o conhecimento do divino e a origem da divinação, verificará que o aprendizado desse tipo espalhou-se do Egito para o mundo inteiro. Ali, pela primeira vez, muito antes de outros homens, eles remontaram ao berço de toda idéia religiosa, e agora guardam com todo cuidado os primórdios do culto registrados em textos secretos. Treinado nessa sabedoria, Pitágoras, reverenciando secretamente os deuses, fez com que tudo o que dissesse ou acreditasse se tornasse autoridade reconhecida. ...Foi de lá que Anaxágoras previu uma chuva de pedras. ...Sólon também, ajudado pelas opiniões dos sacerdotes egípcios, promulgou leis de acordo com a justiça. ...Foi nessa fonte que Platão se baseou e, depois de visitar o Egito, percorreu regiões superiores do pensamento, ...gloriosamente servindo no campo da sabedoria.

Com poucas exceções, como Luciano, Juvenal ou Tácito, o olhar greco-latino sobre o Egito misturava reverência e curiosidade, e não poucos sucumbiram à doce tentação de peregrinar naquele país tido como o berço da civilização. Assim, muito se escreveu e muito se leu sobre o Egito, como bem demonstram, por exemplo, Burstein (Burstein, 1996) e Hartog (Hartog, 1986). Uma boa amostragem, de resto, são os 11 autores citados por Plutarco, no Sobre Ísis e Osíris, a saber: Helânico de Lesbos (século V a.C.), do qual só restam fragmentos, mas que tratou extensamente do Egito (citado no capítulo 34, 364 D); o macedônio Leão de Pela (século IV a.C.), que escreveu Sobre os deuses do Egito (citado em 23, 360 A); Heráclito do Ponto (século IV a.C.), autor de Sobre os oráculos, onde estabelece um paralelo entre os deuses gregos e egípcios (citado em 27, 361 E); Aristágoras de Mileto (século IV a.C.), de quem se sabe que escreveu dois livros sobre o Egito (citado em 5, 352 F); Eudoxo de Cnido (c. 390-c. 340 a.C.), que estudou astronomia com os sacerdotes egípcios, autor de uma Viagem pelo mundo (citado em 6, 353 B-C; 21, 359 B-C; 30, 363 A; 52, 372 D; 62, 376 C; 64, 377 A); Hecateu de Abdera, que escreveu uma Aigyptiaká sob Ptolomeu I, cerca de 300 a.C. (citado em 6, 353 B; 9, 354 D); Evêmero de Messena (século III a.C.), cuja A inscrição sagrada trata longamente dos deuses egípcios (citado em 23, 360 A-B); Maneto de Sebenito (século III a.C.), grão-sacerdote em Heliópolis sob os dois primeiros Ptolomeus, dedicou sua Aigyptiaká a Ptolomeu II e escreveu também O livro sagrado, Sobre as festas, Sobre o costume e a piedade antigos, Epitome de física, Contra Heródoto e Sobre a preparação do quifi (citado em 9, 354 C-D; 28, 362 A; 49, 371 C; 62, 376 B; 73, 380 D); Mnaséias de Patara (século II a.C.), autor de estudos mitológicos (citado em 37, 364 E-F); Aristo (século I d.C.), que examinou as cheias do Nilo (citado em 37, 365 E); e Hemeu, escritor desconhecido citado unicamente por Plutarco em 37, 365 E, e 42, 368 B, que escreveu As festas dos egípcios.

Com certeza Plutarco conheceu outros autores, embora não os cite, a começar por Heródoto, contra quem, aliás, compôs um livro inteiro. Afora Diodoro da Sicília, cujo livro I da Biblioteca histórica é inteiramente dedicado ao Egito, temos notícia de muitos outros, dos quais conhecemos os nomes e as obras por fragmentos, a exemplo de Apolônides Horápio, que escreveu sobre a história e a religião egípcias; Filisto de Naucrátis, autor de Sobre a teologia dos egípcios; Asclepíades de Mendes, que produziu um trabalho específico a respeito da escrita egípcia, Sobre os hieróglifos; Lisímaco de Alexandria, a quem se deve uma Aigyptiaká; e Palefato, autor de um trabalho intitulado Teologia egípcia. 
Havia muito que ver, aprender, anotar naquela terra que se considerava como o repositório da sabedoria do passado. A dificuldade da língua era superada por solícitos intérpretes nativos, ao que se acredita sacerdotes dos escalões inferiores que falavam com desembaraço o idioma do conquistador. O problema maior residia mesmo na leitura das fontes, expressas numa escrita estranha e indecifrável. Indecifrável? Claro que não, porquanto os próprios sacerdotes a liam, mas era impossível, em poucos meses, ensinar a um estrangeiro tudo que pretendia saber (e não necessariamente ler tal escrita) a partir de uma gramática tão diferente da que estava acostumado. Assim, esses homens cultos contentavam-se com informações superficiais, e sua interpretação dos hieróglifos bem demonstra a incapacidade dos gregos de entender a lógica mítica dos egípcios, que tendiam a converter em exposições alegóricas, conforme os termos abstratos de sua própria filosofia. No século I a.C. Diodoro da Sicília (III, 4, 1-2) ilustrava esse procedimento ao explicar que a escrita dos egípcios "não exprime o conceito que pretende por intermédio de sílabas ligadas umas às outras, mas por meio de significados dos objetos que foram copiados e por seu sentido figurativo, impresso na memória pela prática”. Estava convencido, portanto, de que, por exemplo, "o falcão significa para eles tudo que acontece rapidamente, já que esse animal é praticamente a mais rápida das criaturas aladas. E o conceito representado é então transferido, pela transposição metafórica adequada, a todas as coisas rápidas e a tudo de que a rapidez é própria”. Quatrocentos anos depois Amiano Marcelino $(17,4)$ fazia eco a semelhantes asserções:

Embora não como hoje em dia, quando uma série fixa e fácil de letras expressa qualquer coisa que a mente do homem possa conceber, os antigos egípcios também escreviam, mas com caracteres individuais representavam substantivos e verbos individuais, e às vezes significavam frases inteiras. Por um abutre representavam a palavra 'natureza', porque, como a história natural registra, não há machos entre essas aves; e sob a figura de uma abelha fazendo mel designavam um 'rei', mostrando com essa imagem que a doçura de um soberano deveria ser combinada também com um ferrão.

Na Antigüidade tardia e pela Idade Média, o Renascimento e o século XVII afora, constituiu-se assim uma forma de interpretação dos hieróglifos com uma lógica interna toda particular, mas não é raro um autor discordar de outro, construindo sua própria 'etimologia' de acordo com a conveniência da argumentação, vale dizer, com aquilo que queria provar. Sobretudo, porém, tal interpretação alegórica resultou dos debates filosófico-místicos neoplatônicos, e os hieróglifos, como aponta Iversen (Iversen, 1971, p. 175), nesse contexto "se haviam tornado ilustrações da concepção neoplatônica da natureza simbólica das coisas, revelando, de uma forma única e sem paralelos, as verdadeiras relações entre matéria e idéia, corpo e alma, realidade e arte".

Plutarco situa-se na encruzilhada em que se buscava conciliar a compreensão do transcendente divino com o paganismo tradicional. Adotando a divisão platônica da alma em elementos racionais, espirituais e concupiscentes, advoga a busca incessante da perfeição moral, resultado da liberdade do homem. Do estoicismo, por conseguinte, combate o fatalismo determinista e o panteísmo, assim como discorda do epicurismo, por destruir o Divino. Para ele o ideal de equilíbrio, como demonstra Berardi (Berardi, 1990), estava na 
eusébeia, virtude situada entre duas atitudes viciosas que condenava enfaticamente, a deisidaimonía e o atheótes. Sua maneira de pensar o paganismo, por outro lado, foi muito bem resumida por Petit (Petit, 1967, p. 200):

A teologia é para ele o coroamento de toda filosofia. Na velha religião egípcia de Ísis e de Osíris encontra os elementos de uma visão direta da divindade. Seu deus é pessoal e transcendente, criador do mundo e do bem, o que o obrigará a pôr o problema da origem do mal. Para resolver a antinomia entre esse monoteísmo místico e o politeísmo ao qual continua ligado por seu amor aos poetas criadores de mitos, sobretudo Homero e Hesíodo, imagina que os mitos são os símbolos da verdade, criados num tempo em que o pensamento do homem, ainda na infância, não podia alcançar a verdade pela razão. E aceita não somente os mitos gregos, mas também os de outros países, como o Egito, sendo a Divindade suprema a mesma em todos os povos. Interpretando assim o culto de Ísis, tão difundido entre seus contemporâneos, obedece às tendências de sua época e repudia o excesso de imoralidade e de superstição.

Assim, em sua hermenêutica Plutarco rejeita o evemerismo: "Temos de considerar os mitos", afirma, "não completamente como narrativas [históricas], mas tomar cada um de acordo com sua verossimilhança” (58, 374 E; cf. Platão, Menexeno, 255 A, República, 377 A ss., 414 C ss., e Fedro, 261 E-262 C). Mais ainda, ao aconselhar Cléia, sua interlocutora, sublinha que ela, ao ouvir "os mitos contados pelos egípcios acerca de seus deuses, suas perambulações, mutilações e muitas outras coisas desse tipo", não deveria "imaginar que tudo isso tivesse realmente acontecido da maneira que se conta". E explica o significado simbólico dos mitos, pois a seu ver os egípcios "não chamam Hermes de cão em sentido literal, mas, considerando como o animal distingue o que é amigo e inimigo, como assinala Platão, associam suas qualidades de guarda, vigilância e sagacidade com o mais perspicaz dos deuses. Tampouco acreditam que o Sol emirja do loto como um recém-nascido, senão que esta é a maneira como representam o nascer do Sol, simbolizando seu reacender em meio à umidade" (11, $355 \mathrm{~B})$.

Não há motivo de duvidar que Plutarco visitou o Egito, pois com freqüência invoca, ainda que de modo vago, pessoas que designa como of A,gúptioi, of mšn, pollo... dš, of fere <j, tinšj etc., segundo assinala Hani (Hani, 1976, p. 13). Ao contrário de Heródoto, porém, que fazia questão de sublinhar que relatava o que vira e o que ouvira, Plutarco consultou pelo menos 19 autores e cinco obras anônimas, dentre as quais, como vimos acima, 11 tratam especificamente do Egito, assim como três dos anônimos (Aniversários de Hórus, Livros herméticos e Hinos a Osíris). Além disso, não podia deixar de ver as numerosas inscrições nas paredes dos templos, e talvez tivesse em mãos rolos de papiros que não sabia ler. Não sabia mas perguntava, e das explicações tirava suas próprias conclusões para aceitar ou refutar a interpretação deste ou daquele autor. Os hieróglifos, de fato, com centenas de signos que reproduziam o mundo físico, prestavam-se a toda espécie de interpretação a partir de um conhecimento mínimo adquirido de quem realmente conhecia essa escrita.

Para compreender o alcance da distorção, entretanto, vale a pena deter-se um pouco na própria língua egípcia e em seu sistema de escrita. Os intelectuais não-egípcios da época greco-romana sabiam que os hieróglifos expressavam uma língua e que esta língua se or- 
ganizava com sua morfologia e sua sintaxe. Mas jamais suspeitariam, por exemplo, que as segunda e terceira pessoas do singular tinham o refinamento de apresentar formas diferentes para o masculino e o feminino: sedjem- $k$, 'tu (homem) ouves', mas sedjem- $t j$, 'tu (mulher) ouves'. Tampouco deviam imaginar que a proposição verbal se compunha de elementos que se sucediam em determinada ordem fixa (verbo/sujeito/objeto direto/objeto indireto/determinações adverbiais), ou ainda que a maneira de construir os tempos verbais não correspondia exatamente à sua. Nem por isso a sintaxe egípcia deixava de ser profundamente lógica e coerente.

No concernente à escrita, é claro que todos viam que ela reproduzia figuras quase sempre de forma realística. Ainda hoje emprega-se o termo 'ideografia' para designar esse tipo de escrita, mas tem-se preferido falar em 'logografia' (de lógos, 'palavra', e grápho, 'escrever, gravar, desenhar'), de vez que aí se envolve o emprego direto de sons, e não apenas de idéias figuradas (cf. Gelb, 1965, p. 249-250, e índice, s.v. 'Logography'). Os sistemas logográficos produziram significativos repertórios de sinais consonânticos com a função de morfemas, e na leitura esses sinais adquiriram valor de sílabas, formadas por consoantes simples, que compunham o esqueleto da palavra. Ora, como não conhecemos a vocalização da língua egípcia, e como essa vocalização não é representada na escrita, só muito raramente podemos distinguir as diversas formas de um verbo, por exemplo em $m$ - $d$ $u$, 'falar': na realidade as formas para falar, falou, falará etc. assemelham-se todas do ponto de vista das consoantes. A escrita egípcia, assim, possuía fonogramas constituídos de 24 consoantes básicas para a formação de sílabas e ainda centenas de sinais monossilábicos, dissilábicos e trissilábicos, muitos dos quais podiam servir como 'determinativos' (taxogramas), que expressavam elementos semânticos mas não fonéticos, usados para evitar ambigüidade quando o mesmo desenho expressasse mais de um significado ou fosse empregado em contextos gramaticais diversos.

Ainda no âmbito da escrita, só um conhecedor saberá distinguir a sua orientação, que podia ser sinistrógrada (da direita para a esquerda) ou destrógrada (da esquerda para a direita), com a parte de cima tendo precedência sobre a de baixo. A estética, no entanto, fazia com que os signos se agrupassem em quadrados imaginários, de modo a se combinarem harmoniosamente dois signos horizontais, dois verticais, um vertical e dois pequenos, um horizontal e um pequeno e assim por diante. Evitava-se assim o espaço branco inútil que desequilibraria o conjunto, mas tal sistema levava muitas vezes a transposições gráficas, isto é, à mudança da ordem natural dos signos (ver exposição em Farina, 1927, §§ 49-55, e Davies, 1995, p. 12-14). É fácil verificar o desastre, portanto, de tentar 'interpretar' um grupo isolado de signos como significação de uma palavra ou de um conceito sem o conhecimento real de sua disposição ortográfica e de sua função gramatical.

Afora tudo isso, os autores da época greco-romana pretendiam fazer etimologias sem ter a menor idéia da evolução da língua egípcia em seus mais de três mil anos de vida. Os egiptólogos, com efeito, costumam periodizá-la em 1) egípcio antigo, a língua escrita no Reino Antigo (c. 2700-c. 2200 a.C.); 2) egípcio médio, cuja maturidade se deu no Reino Médio (c. 2100 -c. 1800 a.C.), tida como a língua clássica por excelência; 3) neo-egípcio, corrente durante o Reino Novo (1550-1070 a.C.); 4) demótico, evolução do neo-egípcio que se iniciou no período saíta (26 dinastia, 664-525 a.C.) e continuou em uso na época greco-romana até a cristianização do Egito, no século II d.C.; e 5) o copta, que é o egípcio do período cristão, suplantado pelo árabe a partir da segunda metade do século VII. Observe-se ainda que no copta se distinguiam cinco dialetos; há indícios de que eles existiam no 
período faraônico, mas não são reconhecíveis na língua escrita sem vogais. Aliás, vale ressaltar as profundas diferenças entre um período e outro, a tal ponto que a língua clássica mal podia ser compreendida pela gente comum do período neo-egípcio; como escreveu Erman (Erman, 1923, p. 4, nota 2), "se a escrita, que omite todas as vogais, não encobrisse parte considerável do afastamento, a diferença poderia ser vista como tão grande para nós como a que separa o antigo alto alemão de nossa língua moderna ou o italiano do latim”.

Para os escritores de expressão greco-latina nada disso era relevante, mesmo para os que sabiam - se é que sabiam - algo dos princípios da leitura dos hieróglifos. Na verdade, como foi assinalado acima, eles não liam ou decifravam os signos, e sim interpretavam um ou outro que julgavam significativo para justificar o que pretendiam provar. A tradução de algum termo, auxiliada com certeza pelo nativo (presumivelmente sacerdote) que de fato o lia, podia ser correta, mas partiam deste ponto para erigir especulações alegóricas na direção mais conveniente a seus argumentos. Não há necessidade de forjar exemplos para ilustrar tal procedimento, pois são abundantes em muitos autores que escreveram sobre o Egito, e Plutarco não foi exceção.

Detenhamo-nos agora, portanto, nas principais etimologias (ou pseudo-etimologias, ou interpretações etimológicas) que apresenta em Sobre Ísis e Osíris. As transcrições do sistema hieroglífico, como se verá a seguir, são interpoladas com nossas letras $e$ ou $o$ para possibilitar a vocalização. Nas 24 consoantes básicas da língua egípcia contam-se cinco 'semivogais', aqui transliteradas $a$ (duas delas), $i, y, u$, enquanto outras cinco consoantes o são com os dígrafos $k h, c h, s h, t j, d j$. As referências ao copta não significam, naturalmente, que essa etapa da língua egípcia, quando a escrita foi vocalizada por influência grega, tenha servido de fonte a Plutarco, mas podem ser usadas como elementos de comparação com os períodos anteriores, ou como registros de evolução da língua, abrigando novas palavras e bom número de estrangeirismos.

- 9, 354 C. "Muita gente acredita, ademais, que o próprio nome de Zeus na terra dos egípcios é Amun, palavra que alteramos para Amon. Na verdade, Maneto de Sebenito pensa que este vocábulo significa 'oculto' ou 'ocultamento'. Hecateu de Abdera, contudo, diz que os egípcios usam esse termo para chamar alguém, pois essa palavra serve para interpelar. Assim, ao se dirigirem ao deus supremo, que acreditavam ser o próprio universo, como a um ser invisível e oculto, rogam-lhe mostrar-se e manifestar-se ante eles, chamando-o de Amun".

A primeira etimologia corresponde de fato ao egípcio imen, 'oculto, escondido', ‘secreto, misterioso' (DLE, vol. 1, p. 34; DME, p. 21; HWB, p. 71). A segunda sugere mi ou amin, 'vem!' (DLE, vol. 1, p. 210; DME, p. 104; HWB, p. 323; copta amoini), que figura em invocações aos deuses, e não só a Amon.

- 10, 354 F-355 A. Escreve-se o nome de Osíris "por meio de um olho e um cetro. Alguns interpretam o nome como significando 'o que possui muitos olhos', pois na língua egípcia os quer dizer 'muito', e iri, 'olho””. No capítulo 51, 371 E, dá outra interpretação, ao consignar que o olho e o cetro respectivamente "indicam previsão e poder".

A explicação da escrita do nome Osíris é correta, pois constituía a forma gráfica usual na época greco-romana: o olho, irt, ir (EG, na lista de signos D 4; DLE, vol. 1, p. 46; DME, p. 25; HWB, p. 87), e o cetro uas (EG, na lista de signos S 40; Wilkinson, 1994, p. 180-181) formariam o nome Uasirt, Uasir. A forma tradicional era Usir, grafado com o 
assento (EG, na lista de signos Q 1) e o olho. Entretanto, a palavra 'muitos' é asha, e aqui Plutarco (como também Diodoro da Sicília, I, 11,2) parece admitir uma etimologia popular (diferente da primitiva) que surgiria no copta como osh ire, com o mesmo sentido acima: ver Helck (Helck, 1962, coluna 469). A etimologia em geral aceita, proposta por Sethe (Sethe, 1930, § 94), é as(t) ir, 'assento do olho'. Para discussão de outras etimologias, ver Helck (Helck, 1962, colunas 469-470). A segunda explicação de Plutarco carece de fundamento, devendo-se ao hábito grego de interpretações simbólicas de signos isolados.

- 10, 355 A. "O céu, que não envelhece porque é eterno, eles o escrevem com uma cobra, e "cólera' com um coração em cima de um braseiro".

Plutarco registra a crença egípcia de que a cobra não envelhece, e aqui deve referirse ao signo da palavra cobra, djet (EG, na lista de signos I, 10; DME, p. 317), com o qual se escrevia a palavra homônima 'eternidade' (EG, na lista de signos N 16; DLE, vol. 4, p. 146; DME, p. 317).

Quanto ao coração, ib (EG, na lista de signos F 34; Wilkinson, 1994, p. 76-77; DLE, vol. 1, p. 26; DME, p. 14; HWB, p. 38), o signo figura em muitas palavras que expressam sentimentos e emoções, enquanto o braseiro, khet (EG, na lista de signos Q 7), compõe termos que envolvem 'paixão forte', 'ardor' etc. Em vocábulos como iabu, 'desejar, amar, querer', ou no homônimo que significa 'queimar, encolerizar-se', e numa expressão como ta ib, 'irascível', literalmente 'quente de coração', aparecem ambos os signos em conjunto.

- 12, 356 A. Haroéris "é chamado de Hórus o Velho pelos egípcios”.

Haroéris é tradução grega do egípcio Hor Ur, 'Hórus o Grande', provavelmente para distingui-lo do Hórus do culto real e das demais formas do deus, ou para não confundir essa forma solar com o Hórus filho de Ísis, Harpócrate ou Harsiésis.

- 17, 357 E. Os egípcios cantam nos seus banquetes em honra a Manero, dizendose que ele foi o criador da música, "porém há quem sustente que o nome não designa qualquer pessoa, mas é uma palavra que surge entre homens que bebem e se divertem: "boa sorte para isto e para aquilo!' Tal é o sentido da palavra manero expressa pelos egípcios".

O nome já aparece em Heródoto, II, 79, como filho único de Menés, primeiro rei do Egito; falecido prematuramente, passou a ser objeto de lamentos em canções. Os gregos identificavam-no a Lino, o qual, segundo uma das versões do mito, teria sido um cantor tão célebre que Apolo o matou por ciúme. Plutarco reteve essa tradição, não confirmada pelas fontes egípcias até agora conhecidas, mas a expressão de boa sorte pode corresponder a equivalentes como men er neheh, 'que (fulano) dure para sempre', ou men renk, 'que teu nome permaneça', ou ainda men iri, 'que eu dure'.

- 19, 358 C. Tuéris, a concubina de Tifão.

A forma egípcia provável do nome Tuéris é Ta-Urt, 'A Grande', deusa-hipopótamo que protegia os nascimentos, as mulheres e os mortos, tida como símbolo da fecundidade; o hipopótamo macho, ao contrário, é um animal tifoniano, símbolo do mal (50, 371 C-D). O segundo elemento do nome tem no copta a forma yer, 'grande'.

- 20, 359 B. "Alguns interpretam o nome da cidade [de Mênfis] como 'Abrigo do Bom', outros como ‘Tumba de Osíris”," 
A primeira expressão corresponderia hipoteticamente a Meni Nefer (o termo nefer realmente é epíteto do deus), a segunda a Menu Usir, mas nenhuma delas aparece em fontes egípcias até agora conhecidas. Ora, como os termos para 'porto, abrigo' (meniut: DLE, vol. 1, p. 218; DME, p. 108; HWB, p. 336) e 'morrer' (meni: DLE, vol. 1, p. 217; DME, p. 108; HWB, p. 337) são foneticamente próximos, tudo indica que a segunda expressão constitui uma interpretação da primeira.

- 21, 359 C. "Nem é preciso demonstrar que [o corpo de Osíris] se acha em Tefosíris, posto que o próprio nome significa "tumba de Osíris"”.

Plutarco, que diz seguir Eudóxio, refere-se decerto a Taposíris (Tapóseiris), a sudoeste de Alexandria, centro de culto osiriano fundado no início do período ptolomaico: ver Kees (Kees, 1932, coluna 2259), que cita as referências de autores clássicos sobre a cidade. O nome moderno, Abusir, corresponde ao egípcio Per Usir, 'Morada de Osíris', e a alteração da grafia no grego resultou da necessidade de apoiar a pseudo-etimologia como 'tumba de Osíris': táphos Ósiris.

- 29, 362 D. “Quanto a mim, acho que, caso o nome Sarápis seja egípcio, denota prazer e alegria, baseando minha opinião no fato de os egípcios chamarem de Sairei sua festa de regozijo".

A etimologia de Plutarco não tem fundamento, visto que o nome se origina, em egípcio, da junção Usir-Hep (= Osíris-Ápis). Em alguns documentos bilíngües, com efeito, o grego Sarápis traduz Usir-Hep, como em uma pequena lâmina de ouro encontrada num santuário de Mênfis da época de Ptolomeu IV (221-205 a.C.) e em inscrições gregas e demóticas; em muitos papiros consigna-se até o equivalente mais exato Oserápis (por exemplo no Papiro Artemísia, do século IV a.C., e Osorápis, nos papiros do Sarapium de Mênfis, dos séculos III e II a.C.). A forma Sarápis resultou do equívoco de considerar-se a letra $o$ inicial como um artigo.

No referente à festa de regozijo, o termo sairei (sairi) não existe na língua egípcia; o vocábulo que designa 'gestos de alegria', 'regozijo', 'gritos de júbilo', 'aclamações' etc. é henu (DLE, vol. 2, p. 84; DME, p. 159; HWB, p. 494). A palavra devia ser recente, pois se aproxima do copta sairi, 'alegria', 'festividade', mas Plutarco podia ter em mente o verbo grego chaíro, 'rejubilar-se'.

- 29, 362 D. "O lugar subterrâneo para onde [os egípcios] crêem que as almas vão depois da morte, Amente, quer dizer 'aquele que recebe e dá"”.

A descrição e a transcrição do nome, do egípcio Amenti (tardio Imentet), são corretas, mas não a etimologia, pois significa 'Oeste', a morada dos mortos ou dos 'ocidentais', imenty $u$, regida por um deus-chacal, assimilado a Osíris, chamado Khenti-imentyu, 'Primeiro dos ocidentais'.

- 32, 363 F. "Em Saís, no pilão fronteiro do templo de Atena, havia gravada uma inscrição representando uma criança, um velho, depois um falcão, em seguida um peixe e por fim um hipopótamo. O significado simbólico disso era: 'Ó vós, os que nascem e morrem, o deus odeia a impudência'. A criança é o símbolo do nascimento, o velho da morte; com um falcão indicam o deus, com um peixe o ódio, como já dissemos, por causa do mar, e com um hipopótamo a impudência, porque, segundo se diz, após matar seu pai, violenta sua mãe". 
A 'tradução' de Plutarco é completameste equivocada, correspondendo na verdade à pseudo-etimologia praticada na época greco-romana, isto é, retinha-se apenas o elemento ideográfico que servia de determinativo à palavra escrita foneticamente. Entretanto, o informante de Plutarco interpretou de forma correta os signos de criança, cherd (EG, na lista de signos A 17; Wilkinson, 1994, p. 20-21; DLE, vol. 2, p. 212; DME, p. 204; HWB, p. 643); de velho, iau (EG, na lista de signos A 19; DLE, vol. 1, p. 15; DME, p. 8; HWB, p. 23); e de deus, netjer (EG, na lista de signos G 7 e p. 576; DLE, vol. 2, p. 40; DME, p. 142; HWB, p. 443; cf. adiante, 51,371 E). A leitura de peixe como ódio e a de hipopótamo como impudência comportam certa dificuldade. Há um peixe denominado $b u$, e sua figura aparece como determinativo no vocábulo but, 'abominação' (EG, na lista de signos K 2; DLE, vol. 1, p. 154; DME, p. 82; HWB, p. 251), próximo do sentido do grego mîsos. Quanto a hipopótamo, deb (DLE, vol. 4, p. 127; DME, p. 311; HWB, p. 973) e khab (EG, na lista de signos E 25; Wilkinson, 1994, p. 70-71; DME, p. 184; HWB, p. 582), só é possível aceitar o grego anaídeia se acrescentarmos ao sentido do termo as noções de crime, culpa e destruição, tomando a raiz egípcia $k h b$, a mesma que compõe a palavra hipopótamo, e outras como kheba, 'destruição, matança' (DLE, vol. 2, p. 168; DME, p. 187), kheben, 'palavra deturpada' e 'mau caráter' (DME, p. 187; HWB, p. 591), khebekheb, 'esmagar' (DLE, vol. 2, p. 169) e khebenet, 'crime’ (DME, p. 187). Porém não há registro, em fontes egípcias, de relação da impudência de Set/Tifão ou de seu animal, o hipopótamo, com atos combinados de parricídio e incesto, embora Set se associe de fato a noções como distúrbio, crueldade, tumulto, arrogância, maldade, violência etc. Cf. Velde (Velde, 1977, p. 22-23).

- 33, 364 C. "Como o Egito possui o mais negro dos solos, eles o denominam com o mesmo nome da parte negra dos olhos, Quemia".

Os egípcios, com efeito, chamavam seu país de Kemet, 'Terra Negra', em oposição a desheret, 'terra vermelha', isto é, o deserto. O adjetivo kem, 'negro, escuro', podia designar a pupila, mas com certeza a etimologia egípcia remete à lama escura que dava fertilidade ao solo.

- 34, 364 D. "Também chamam Dioniso de Hýes, como senhor da natureza úmida, sendo ele próprio Osíris. De fato, Helânico parece ter ouvido Osíris pronunciado Hisíris pelos sacerdotes, daí ele sempre chamar esse deus assim, provavelmente derivado de hýsis, 'chuva', e rhýsis, 'escoamento [de água]"”.

Com essa etimologia Plutarco pretende mostrar que Osíris é a água fertilizante, e embora existisse a forma Ysir na época ptolomaica, ao lado da tradicional Usir, a explicação confina-se ao limite do simbólico.

- 36, 365 B. “Escrevem com um junco 'rei' e 'região meridional do mundo', sendo o junco interpretado como a irrigação e a gestação de todas as coisas, e em sua natureza parece assemelhar-se ao membro sexual da geração".

Plutarco refere-se a nisut, nesu, 'o que pertence à planta sut', expressão que designava 'rei do Alto Egito' (EG, na lista de signos M 23 e 24; DME, p. 139; HWB, p. 431). Essa planta ainda não foi identificada, mas seu desenho assemelha-se ao do junco, nekheb, que aparece em nekhebet com os significados de 'germinação' e de 'crescer, brotar' (EG, na lista de signos M 22). A imagem que associa junco e falo deve ser de origem grega: em Aristófanes, Vespas, 1342-1343, o membro viril é denominado justamente schoiníon, 'corda de junco'. 
- 37, 365 E. "A hera é ...chamada de chenósiris pelos egípcios, palavra que significa, como eles afirmam, "planta de Osíris"”.

Segundo Diodoro da Sicília, I, 17, 4, a descoberta da hera deveu-se a Osíris, e por isso os egípcios consagravam-na a este deus. O poeta Tibulo, I, 7, 45, diz que as estátuas de Osíris eram ornadas com hera, e Apuleio, Metamorfoses, XI, 27, que seus sacerdotes a exibiam no culto. Plutarco é o único a assinalar o vocábulo chenósiris, que não se atesta em textos egípcios; corresponderia hipoteticamente a khet-en-Usir, copta chenusir, mas a hera sequer é identificada na flora egípcia, certamente introduzida tardiamente pelo culto ptolomaico. Ver Sethe (1899).

- 37, 365 E. “Aristo ...descobriu uma carta de Alexarco na qual se dizia que Dioniso era filho de Zeus e de Ísis, não sendo chamado de Osíris, mas de Arsafe, nome que denota ‘virilidade'. Também Hermeu expressa tal opinião, ...pois diz que o nome Osíris, adequadamente interpretado, significa "vigoroso","

Arsafe é o deus-carneiro Heryshef, cultuado sobretudo em Heracleópolis, capital do vigésimo nomo do Alto Egito. Apesar de esse deus identificar-se a Osíris e de os egípcios associarem o carneiro a virilidade e vigor sexual, trata-se de uma pseudo-etimologia, pois o nome Heryshef significa 'O que está em seu lago', provável alusão à lagoa do principal templo da cidade, que representava o Nun, as águas primordiais de onde saíra a vida. A confusão pode dever-se à assonância de Usir (Osíris) com user, 'vigoroso, forte, poderoso' (DLE, vol. 1, p. 128; DME, p. 68; HWB, p. 215), ou de Heryshef com shef, shefit, shefeshefet, 'dignidade, autoridade', mas também 'respeito, medo' (DLE, vol. 3, p. 146-148; DME, p. 265; HWB, p. 817), o que remete às idéias de poder e vigor.

Na tradução do texto grego preferi, em virtude do contexto, a lição óbrimon, 'vigoroso', em vez de ómbrimon, 'úmido'.

- 41, 367 D. "O Sol, por seu fogo ardente e dessecante, aquece e consome a vegetação tenra, e devido à sua luz brilhante torna inabitável a maior parte da Terra... Por isso os egípcios dão a Tifão o nome de Set, que significa 'o que oprime e obriga'”. Cf. 49, 371 BC: "Tifão é na alma o elemento passional, titânico e instável, bem como tudo que no corpo do cosmo é perecível, doentio e desordenado, como as irregularidades das estações, as intempéries, os eclipses do Sol e os desaparecimentos da Lua, que são formas de presença e da ação turbulenta de Tifão. Isso é o que denota o nome Set, como chamam Tifão, que significa 'opressão' e 'jugo', querendo dizer também com freqüência 'retrocesso' e 'transgressão’. Alguns afirmam que Bebo foi um dos companheiros de Tifão, porém Maneto sustenta que o próprio Tifão é igualmente chamado de Bebo; o nome indica 'obstáculo' ou ‘impedimento', como se quisesse dizer que quando as coisas seguem seu curso natural e são impulsionadas para um fim justo, Tifão a elas se opõe”. No capítulo 62, 376 A-B, afirma que Tifão "é chamado de Set, Bebo e Smu, nomes que expressam algo como "impedimento violento' e 'oposição' ou 'reversão"”.

A explicação de Plutarco desvela a natureza do deus Set, mas a etimologia é falsa. Segundo Kees (Kees, 1923, coluna 1897) essa pseudo-etimologia deriva de interpretações egípcias tardias, referindo-se a verbos que significam (em alemão) werwirren, "emaranhar, confundir, complicar', e zerstückeln, 'despedaçar, fragmentar', nos prováveis correspondentes egípcios tekhetekh, 'confundir, desordenar', teshetesh, 'separar, dividir', mas também 'golpear, bater' e 'triturar, pisar, moer, esmagar', tesh e seu sinônimo tesha, 'fender, 
rachar, partir'. Assim, o nome Set (egípcio Setesh, Setekh, copta Set), como sugere Kees, foi vinculado a um verbo precedido de $s$, letra que, prefixada a este, empresta-lhe valor causativo ou estimativo para declarar ou avaliar algo. A explanação de Plutarco pode também remeter aos verbos set, 'quebrar, cortar', e setja, 'puxar, extrair, arrancar', e ainda 'arrastar' e 'rasgar'. De qualquer modo, o nome do deus refere-se particularmente a distúrbio, desastre, violência, aflição, crueldade, confusão etc., mas sua verdadeira etimologia continua objeto de discussão: entre outros ver Kees (Kees, 1923, coluna 1897), Roeder (Roeder, 1965, coluna 727), Scharff (Scharff, 1948, p. 44, nota 100) e Velde (Velde, 1977, p. 3-7).

Bebo é o nome grego de Baba (também Babui e Baby), divindade turbulenta e maligna; com efeito, nos Textos dos sarcófagos ele faz "vacilar as horas da noite", "os homens tremem diante dele" e "aquele que o vir não viverá" (CT, recitação 668), e no Livro dos mortos aparece como o deus "que vive de suas vítimas, que guarda o circuito do lago de Fogo, que engole cadáveres, que rapta os corações e que espalha os miasmas sem ser visto" (LM, capítulo 17; cf. capítulo 125). O Papiro Jumilhac confirma a assimilação com Set, ao registrar que "o cão vermelho é Baba, e Baba é Nebedj (= Set)". Plutarco, aqui, acerta na identificação, equivocando-se porém na etimologia. Ver Derchain (Derchain, 1952 e 1963).

Por fim, o nome Smu, de acordo com Kees (Kees, 1923, coluna 1897), pode referirse a um demônio, mas provavelmente designa os aliados de Set, semait (cf. o verbo sema, semai, 'unir, juntar-se, copular'). Griffiths (Griffiths, 1970, p. 522) sugere ainda que a palavra aludiria a Set como touro de sacrifício, chamado de sema, abatido na qualidade de inimigo de Osíris e Hórus.

- 42, 368 B. "Osíris é benfeitor, e seu nome, que possui vários sentidos, expressa sobretudo o poder ativo e benfazejo, como assinalam [os egípcios]. O outro nome do deus é Onfis, que segundo a interpretação de Hermeu significa 'benfeitor'”.

O nome Onfis (Ómphis) é variante de Onófris (Ónnophris), que corresponde ao egípcio Unen-nefer (também Un-nefer), traduzível como ‘Aquele que é bom' ou 'belo', ou 'Ser bom': cf. Rusch (Rusch, 1939, colunas 483-484). Este sentido de bom, benfazejo, belo, é o habitual, mais ou menos seguido, por exemplo, por Kees (Kees, 1941, p. 114), que traduz a expressão por 'O que existe em bondade (formosura)', e por Alan Gardiner (apud Griffiths, 1970, p. 461), que lhe dá o significado de 'O que está em estado de permanente ser bom'. Diversamente, Jéquier (Jéquier, 1946, p. 51-54) confere ao adjetivo nefer uma aplicação ritual, referindo-se não a bondade ou beleza, mas à regeneração por meio de ritos, o que altera a tradução para 'O que se regenera' ou 'Ser regenerado', interpretação seguida por Helck (Helck, 1962, coluna 503). Plutarco, portanto, reteve o significado hoje ainda correntemente seguido, que abriga as noções de bom, benfazejo, benfeitor.

- 50, 371 C-D. “Em Hermópolis [os egípcios] mostram uma estátua de Tifão como hipopótamo, em cujo dorso se acha um falcão em luta com uma serpente. O hipopótamo representa Tifão, e o falcão poder e autoridade, que Tifão se empenha em obter pela força".

O hipopótamo (= Set) abatido pelo deus-falcão Hórus é um tema corrente na iconografia religiosa egípcia. No templo ptolomaico de Edfu existem abundantes exemplos, onde em várias cenas vemos Hórus, de sua barca, ferir com um arpão o hipopótamo no focinho, no pescoço, nos flancos, no dorso, nos testículos, no traseiro e nas patas, após o que seria retalhado; apenas uma cena mostra o deus-falcão no dorso do hipopótamo, cuja cabeça trespassa com o arpão: ver Fairman (Fairman, 1974, p. 109, fig. 14). Na estela de 
Metternich também se encontra motivo similar, só que o animal é o crocodilo: uma das representações aproxima-se da descrição de Plutarco, visto que Hórus aparece sobre um crocodilo, com uma serpente acima da cabeça do deus (Moret, 1915, prancha I, registro IV), enquanto Hórus sobre um hipopótamo só é figurado uma vez, sem o acompanhamento de qualquer serpente (Moret, 1915, prancha VI, registro XXVIII). Sobre o hipopótamo como animal setiano ver Hani (Hani, 1976, p. 434-437) e Wilkinson (Wilkinson, 1999, p. 176-179).

A serpente não foi interpretada por Plutarco, mas figurava entre os animais setianos (cf. capítulo 19, 358 C-D). Entretanto, como vimos, não se conhece na iconografia egípcia qualquer representação de Hórus em luta com uma serpente no dorso de um hipopótamo. falcão".

- 51, 371 E. "Muitas vezes escrevem também o nome desse deus [Osíris] com um

No capítulo 32, 363 F (ver acima) Plutarco diz que "com um falcão [os egípcios] indicam o deus". Normalmente o signo designaria Hórus, já que o falcão era o seu animal, mas o hieróglifo do falcão sobre um poleiro (EG, na lista de signos R 13; Wilkinson, 1994, p. 166-167; DLE, vol. 1, p. 35; DME, p. 21; HWB, p. 72) pode de fato aparecer como determinativo de divindade, inclusive de Osíris, além de representar o Amenti, 'Oeste' (ver comentário acima de 29, 362 D). Cf. Hare (1999, p. 161).

- 56, 374 B. "Eles têm igualmente o costume de chamar Hórus de Min, que significa 'aquele que vê', pois o cosmo é perceptível e visível".

O verbo egípcio maa significa 'ver' (DLE, vol. 1, p. 203; DME, p. 100; HWB, p. 314), e conjugado aproxima-se foneticamente do nome do deus Min (Menu), por exemplo em maa-i nu, 'eu vejo', ou maa-n-i, 'eu vi', mas decerto se trata, em Plutarco, de uma pseudo-etimologia.

- 56, 374 B. "Ísis é às vezes chamada de Mut, outras de Atiri ou Metier. O primeiro nome quer dizer 'mãe', o segundo 'habitação cósmica de Hórus' ou, como diz Platão, 'lugar e receptáculo da geração', e o terceiro compõe-se de duas palavras, 'cheio' e 'harmonioso', porquanto a matéria do cosmo é cheia e se associa ao bem, ao puro e ao ordenado".

O substantivo mut, 'mãe' (EG, na lista de signos G 14; Wilkinson, 1994, p. 84-85; DLE, vol. 1, p. 215; DME, p. 106; HWB, p. 330) e o nome da deusa Mut (EG, na lista de signos G 15) eram ambos representados por um abutre; a divindade, tida como a mãe por excelência, foi absorvida por Ísis na época tardia.

Atiri corresponde à deusa Hator, em egípcio Het-Hor, 'Habitação de Hórus', nome grafado com o falcão Hórus numa casa (EG, na lista de signos C 9 e O 10). A interpretação de Plutarco, provavelmente no espírito da época ptolomaica, funda-se em que já nos Textos das pirâmides existia a noção de o céu ser a 'habitação de Hórus', em que Hator era uma deusa celeste e em que justamente no céu o falcão fazia suas evoluções.

O nome Metier pode remeter-se ao egípcio Mehet-Urt, 'Grande Inundação', que evoca o caos das águas primordiais de onde surgiu o cosmo, na verdade epiclese de Hator sob seu aspecto de vaca celeste, representando aquele caos: cf. Kees (1941, p. 75-76) e alusões em $P y r$, , $\S 508$ e 1131. A grafia grega afasta-se do egípcio no segundo elemento (urt, 'grande'), mas aproxima-se do copta Muh Yer.

-62, 376 A. "Os egípcios ...chamam Ísis pelo nome de Atena, o qual significa algo como "vim de mim própria', indicando movimento de auto-impulsão". 
Atena aqui designa sem dúvida a deusa Neit (egípcio Net) de Saís, identificada àquela divindade grega (cf. Arnóbio, IV, 16; Eusébio, Preparação evangélica, III, 2, 6-7; Hesíquio, s.v. 'Neith'; e Heródoto, por exemplo II, 28, 59 e 83) e em seguida a Ísis; o próprio Plutarco consigna, no capítulo 9, 354 C, que em Saís (aliás centro de culto de Neit) havia uma estátua de Atena, que os egípcios "acreditavam ser Ísis", com a inscrição: "Sou tudo o que foi, o que é e o que será, e meu véu jamais foi levantado por qualquer mortal". A etimologia liga-se no período ptolomaico ao nome Nut, e Rusch (Rusch, 1935, coluna 2190) indica uma ligação entre Net (Neit) e netet, 'o que é', ou ainda a assonância com nai, 'vir' (copta na). A interpretação do significado vem decerto de Platão, Fedro, 245 C-246 A, para quem Atena é automotriz e inengendrada.

- 68, 378 B. “O amuleto de Ísis, que segundo os mitólogos ela prende em torno do pescoço, é interpretado como "voz verdadeira"”.

O simbolismo original desse amuleto, denominado 'nó isíaco', deriva do signo ankh, 'vida' (EG, na lista de signos S 34; Wilkinson, 1994, p. 176-177, e 1999, p. 159-161; DLE, vol. 1, p. 80; DME, p. 44; HWB, p. 145), mas a interpretação corresponde à fórmula maat kheru, 'verdadeiro de voz' ou 'justo de voz'; como explica Gardiner (EG, § 55), "originariamente aplicou-se a Osíris em referência à ocasião em que seus direitos régios, contestados por Set, foram defendidos ante o tribunal divino em Heliópolis”. Observe-se, de resto, que a deusa Maat, 'Verdade', 'Justiça', portava na mão justamente o amuleto ankh. Assim, uma confusão entre a efígie de Maat e o amuleto (cf. Diodoro, I, 48, 6; 75, 5) pode ter originado a interpretação de Plutarco.

- 68, 378 C. Harpócrate é representado com “o dedo sobre os lábios, como símbolo de discrição e silêncio".

Harpócrate é o nome grego do egípcio Hor pa Cherd, 'Hórus Menino', procriado da união entre Ísis e Osíris morto (ver capítulo 20, 358 D-E). Representado como uma criança sentada no colo e levando a mão à boca (EG, na lista de signos A 17; Wilkinson, 1994, p. 20-21), assim é descrito nos Pyr., $\S 663$ e 664. Os gregos viam esse deus menino como fraco dos membros inferiores em virtude do nascimento prematuro (cf. no próprio Plutarco, capítulo 19, 358 E), mas os textos egípcios não confirmam tal patologia. Também interpretaram erroneamente o signo de 'criança' - e é o caso aqui -, dando-o como um convite ao silêncio, vale dizer, a não se revelar segredos iniciáticos, e o hieróglifo passou a ser o símbolo mais célebre do pretenso esoterismo egípcio.

- 79, 383 D. "Entre os egípcios se chama a mirra de sal", termo "interpretado com o sentido de "disseminação"”.

A etimologia aqui seria abrigada no copta shal, correspondente ao egípcio antyu, 'mirra' (DLE, vol. 1, p. 81; DME, p. 44; HWB, p. 148); o significado de 'disseminação' (em grego ekskorpismós) só poderia ser aceito caso se ampliasse para 'disseminação de odor' ou equivalente.

- 80, 383 E. "O quifi é uma mistura de 16 ingredientes”.

O nome grego kyphi traduz o egípcio kap, 'fumigar, queimar' (DME, p. 284; HWB, p. 875). O número de ingredientes em sua composição, no entanto, varia nos textos da época faraônica. Ver Hani (Hani, 1976, p. 285-286). 
Finalmente, é interessante verificarmos, a essa altura, como os próprios egípcios construíam suas etimologias. Para entendê-lo, porém, temos de raciocinar em outros termos e apreender outro universo mental muito diferente do que foi legado pela tradição clássica. Para o egípcio, com efeito, as palavras, e em particular os nomes pessoais, constituíam uma espécie de potência em si; os nomes eram inseparáveis dos indivíduos, como algo que definia o ser. Ao que explica Garnot (Garnot, 1954, p. 98), o "nome é um acumulador de forças internas, um reservatório de energias latentes, que podem descarregar-se, por assim dizer, muito facilmente, e cuja liberação não se faz sem perigo. Por isso a revelação de um nome próprio dá ao operador todo poder sobre o ser que ele interpela ao chamá-lo por seu nome". Saber o nome de algo ou de alguém conferia um espécie de domínio sobre o objeto enunciado, e por isso justificava-se, nos textos funerários, o morto proferir nomes de monstros e deuses em seu percurso pelo além ('eu te conheço, sei teu nome, teu nome é...'). Ademais, Erman (Erman,1952, p. 220) observa que "o nome se identifica com a pessoa, e o que acontece ao nome acontece também ao homem que o porta"; daí uma recitação funerária como "que teu nome viva sobre a terra, que teu nome dure sobre a terra, (e assim) nunca perecerás nem serás destruído por toda a eternidade" (Pyr., § 764). O assunto acha-se desenvolvido por exemplo em Davies (Davies, 1995, p. 17-20) e Hare (Hare 1999, p. 157-159).

Entendida essa relação do homem com as palavras, podemos entender também como se formavam as etimologias na língua egípcia. As 'explicações etimológicas' em geral se davam por um jogo de palavras diferentes mas com o mesmo som (paronomásia); como assinala Gilula (Gilula, 1982, p. 260):

... às vezes o som do verbo determina a escolha do nome, enquanto em outros casos o nome influencia a escolha da atividade. ... portador de um nome ou epíteto por vezes o recebia porque possuía determinadas qualidades ou devido a certos atos de sua parte; em alguns casos, um 'nome' pode ser inventado especialmente para uso único, a fim de tornar possível uma ação específica. O respeito com que os antigos egípcios encaravam os nomes e a importância que atribuíam a eles não deixam dúvida de que consideravam essa espécie de jogo de palavras ad hoc como etimologias no sentido estritamente literal da palavra.

Assim, por exemplo, no grande hino a Aton encontramos o verso "és Ra, alcanças o fim das terras" (paronomásia entre Ra e er-ra, 'até o fim'), e nos hinos a Amon do papiro I-350 de Leide, as estrofes numeram-se em capítulos, cada número destes compondo paronomásia com alguma palavra-chave do primeiro ou do último verso da estrofe, como no capítulo 300, onde se afirma que Amon, Ra e Ptah são três deuses em um, "três são todos os deuses" (khemetet, 'trezentos', e khemetu, 'três'). Também era muito empregada a fórmula ren-k pu en, 'em seu nome de', ou 'qualidade', ou 'poder', ou 'identidade', como se queira traduzir, associada a nomes ou epítetos, como ao dizer-se que o deus Ptah "se completou em seu nome de Atum, sendo um único corpo com ele" (paronomásia entre tem, 'estar completo', e Item, o deus Atum).

Os próprios egípcios, de resto, utilizavam desde o Reino Novo a escrita criptográfica para dissimular a leitura de nomes próprios: um exemplo é a estátua que agrupa o deus-Sol $(R a)$, o faraó como criança (mes) e uma planta heráldica $(s u)$; juntando-se os três elementos temos o nome Ra-mes-su (Ramessés). Assim, o significado de qualquer palavra poderia ficar restrito à compreensão imediata de poucas pessoas, preservando-se o nome que se queria 
proteger de poderes mágicos maléficos ou da destruição (ver Wilkinson, 1994, p. 20-21; e Silverman, 1997, p. 241).

Poderíamos prosseguir à exaustão com os exemplos, mas esses bastam para se ver o abismo que separava a formação das etimologias na língua egípcia, por um lado, e na interpretatio graeca por outro. É claro que os hieróglifos possuíam um componente metafórico bastante ativo, como bem demonstra Goldwasser (Goldwasser, 1995; cf. também 1999), mas nem sempre ele é evidente. Tomemos apenas três casos para ilustrar tal dificuldade. $\mathrm{O}$ signo de uma mulher em trabalho de parto é óbvio e realmente significa mesi, 'dar nascimento, parir' (EG, na lista de signos B 3; DLE, vol. 1, p. 240; DME, p. 116; HWB, p. 360); o mesmo verbo, todavia, pode igualmente ser escrito com o pêlo de raposa (EG, na lista de signos F 31) ou ainda com uma mulher dando nascimento a esse pêlo, e não a uma criança (EG, na lista de signos B 4). A explicação disso reside no fato provável de o pêlo de raposa ser uma espécie de fetiche de proteção à mulher, e assim esse estranho signo poderia significar algo como 'nascimento afortunado ou bem protegido'. Em outro caso temos um par de pernas em movimento (EG, na lista de signos D 54) e um pequeno pote (EG, na lista de signos W 24); combinados os dois signos, com o pote sobre as pernas (EG, na lista de signos W 25), temos o verbo ini, 'trazer, conduzir' (DLE, vol. 1, p. 36; DME, p. 22; HWB, p. 74). Essa imagem surrealista é esclarecida pela versão ptolomaica do signo, que mostra um homem conduzindo um pote na mão. Finalmente, o verbo saq, 'reunir, juntar', e também 'cooperar' e 'proteger' (DLE, vol. 3, p. 11; DME, p. 211; HWB, p. 662), é escrito com um crocodilo cuja cauda se curva em direção à parte inferior do seu corpo (EG, na lista de signos I 5). Embora esse réptil, em outras imagens, apareça como determinativo (taxograma) de palavras com significados negativos, como agressividade, voracidade etc., aqui o verbo saq só figura com conotações positivas, o que se liga a uma antiga divindade, Saq, que teria reunido os ossos de Osíris esquartejado.

Assim, a junção de signos que leva ao que Goldwasser (Goldwasser, 1995, p. 20-21) chamou de "metáforas fonéticas" ou a intrusão mitológica que resulta em significados desconcertantes, jamais poderiam ser apreendidos em sua verdadeira inteireza sem um conhecimento profundo da própria cultura faraônica e dos princípios ortográficos e gramaticais de sua escrita. A interpretatio graeca limitava-se em boa parte à aparência óbvia dos taxogramas, não raro chegando a resultados desastrados em virtude de interpretações equivocadas ou tendenciosas por definição. Plutarco mesmo (10, 354 E) dá a chave de seu procedimento ao dizer que Pitágoras, imitando o simbolismo e os ensinamentos secretos dos egípcios, "envolveu sua doutrina em enigmas; aliás, não existe nenhuma diferença entre os textos chamados de hieróglifos e a maioria dos preceitos pitagóricos". Autores como Allen (1970), David (1965), Iversen (1971, mas sobretudo 1993) e Singer (1989), entre outros, demonstram como a tradição alegórica na interpretação dos hieróglifos sobreviveu até o verdadeiro deciframento por Champollion, em 1822, gerando no entanto resultados que escaparam por completo ao estrito domínio da etimologia, em caminhos os mais diversos e insuspeitados. Plutarco, aliás, ainda que em âmbito restrito, é afinal um bom exemplo disso.

\section{Referências bibliográficas}

ALLEN, Don Cameron. Mysteriously meant: the rediscovery of pagan symbolism and allegorical interpretation in the Renaissance. Baltimore: Johns Hopkins University Press, 1970. 
BABBITT, Frank Cole. Plutarch's Moralia. $3^{\mathrm{a}}$ reimpr. 16 vols. Londres: William Heinemann. Cambridge, Mass.: Harvard University Press, vol. 5, 1969.

BARGUET, Paul. Le Livre des Morts des anciens égyptiens. Paris: Cerf, 1967.

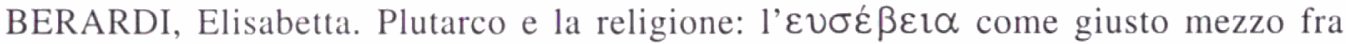

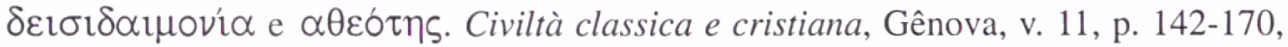
1990.

BURSTEIN, Stanley M. Images of Egypt in Greek historiography. In: LOPRIENO, Antonio (Ed.). Ancient Egyptian literature: history and forms. Leide: E. J. Brill, p. 591-604, 1996.

BUCK, Adriaan de. The Egyptian coffin texts. 7 vols. Chicago: The University of Chicago Press, 1935-1961.

DAVID, Madeleine. Le débat sur les écritures et l'hiéroglyphe aux XVII et XVIII siècles et l'application de la notion de déchiffrement aux écritures mortes. Paris: SEVPEN, 1965.

DAVIES, W. V. Egyptian hieroglyphs. 8a impressão. Londres: British Museum, 1995.

DERCHAIN, Philippe. Bébon, le dieu et les mythes. Revue d'Égyptologie. Paris, v. 9, p. 2347, 1952.

DERCHAIN, Philippe. Nouveaux documents relatifs à Bébon. Zeitschrift für Ägyptische Sprache und Altertumskunde. Berlim, v. 90, p. 22-25, 1963.

LESKO, Leonard H. (Ed.). A dictionary of late Egyptian. 5 vols. Berkeley: B. C. Scribe, 1982-1990.

FAULKNER, Raymond O. A concise dictionary of Middle Egyptian. 6. impr. Oxford: Griffith Institute, 1991.

GARDINER, Alan. Egyptian grammar. 3. ed. rev., 2. impr. Londres: Oxford University Press, 1966.

ERMAN, Adolf. Die Literatur der Aegypter. Gedichte Erzählungen und Lehrbücher aus dem 3. und 2. Jahrtausend v. Chr. Leipzig: J. C. Hinrichs, 1923.

1952 La civilisation égyptienne. Tradução de Charles Mathien. Paris: Payot, 1952.

FAIRMAN, H. W. The triumph of Horus: an ancient Egyptian sacred drama. Londres: B. T. Batsford, 1974.

FARINA, J. Grammaire de l'ancien égyptien (hiéroglyphes). Tradução de René Neuville. Paris: Payot, 1927.

FROIDEFOND, Christian. Plutarque. Oeuvres morales, vol. 5, segunda parte: Isis et Osiris. Paris: Les Belles Lettres, 1988.

GARNOT, Jean Sainte Fare. L'hommage aux dieux sous l'Ancien Empire égyptien, d'après les Textes des Pyramides. Paris: Presses Universitaires de France, 1954.

GELB, I. J. A study of writing. Ed. rev. Chicago: The University of Chicago Press, 1965.

GILULA, Mordechai. An Egyptian etymology of the name of Horus? Journal of Egyptian Archaeology. Londres, v. 68, p. 259-265, 1982. 
GOLDWASSER, Orly. From icon to metaphor: studies in the semiotics of the hieroglyphs. Friburgo, Suíça: University Press. Göttingen: Vandenhoeck \& Ruprecht, 1995.

GOLDWASSER, Orly. The determinative system as a mirror of world. Göttinger Miszellen. Göttingen, v. 170, p. 49-68, 1999.

GRIFFITHS, J. Gwyn. Plutarch's De Iside et Osiride. Cardiff: University of Wales Press, 1970.

HANI, Jean. La religion égyptienne dans la pensée de Plutarque. Paris: Les Belles Lettres, 1976.

HANNING, Rainer. Grosses Handwörterbuch Ägyptisch-Deutsch (2800-950 v. Chr.). 2. ed. Mainz: Philipp von Zabern, 1997.

HARE, Tom. Remembering Osiris: number, gender, and the word in ancient Egyptian representational systems. Stanford: Stanford University Press, 1999.

HARTOG, François. Les Grecs égyptologues. Annales. Economies, Sociétés, Civilisations. Paris, v. 41, p. 953-967, 1986.

HELCK, Wolfgang. Osiris. In: RE, suplemento 9, colunas 469-513, 1962.

HOPFNER, Theodor. Plutarch: Über Isis und Osiris. Übersetzung und Kommentar. 2 vols. Praga: Orientalisches Institut, 1940-1941.

IVERSEN, Erik. The hieroglyphic tradition. In: HARRIS, J. R. The legacy of Egypt. 2. ed. Oxford: Clarendon, p. 170-196, 1971.

. The myth of Egypt and its hieroglyphs in European tradition. 2. ed. Princeton: Princeton University Press, 1993.

JÉQUIER, Gustave. Considérations sur les religions égyptiennes. Neuchâtel: La Baconnière, 1946.

KEES, Hermann. Seth. In: RE (segunda série), v. 2, tomo 2, colunas 1896-1922, 1923.

Taposiris. In: $R E$, v. 4/A, tomo 2, colunas 2259-2260, 1932.

Der Götterglaube im alten Aegypten. Leipzig: J. C. Hinrichs, 1941.

MORET, Alexandre. Horus sauveur. Revue de l'histoire des religions, Paris, v. 72, p. 213$287,1915$.

PAULYS REALENCYCLOPÄDIE DER CLASSISCHEN ALTERTUMSWISSENSCHAFT. Duas séries (AQ, 24 vols. em 49 tomos; e R-Z, 9 vols. [1/A-9/A] em 19 tomos) e 15 suplementos. Stuttgart: A. Druckenmüller, 1893-1963 (primeira série), 1914-1972 (segunda série), 1903-1978 (suplementos).

PETIT, Paul. La paix romaine. Paris: Presses Universitaires de France, 1967.

SETHE, Kurt. Die altägyptischen Pyramidentexte. Reimpr. reprográfica. 3 vols., 4 tomos. Hildesheim: Georg Olms, 1969.

ROEDER, Günther. Set. In: ROSCHER, W. H. (Ed.). Ausfïhrliches Lexikon der griechischen und römischen Mythologie. Reimpr. reprográfica. 6 vols., 4 suplementos. Hildesheim: Georg Olms, colunas 725-784, 1965. 
RUSCH, Adolf. Neith. In: RE (primeira série), v. 16, tomo 2, colunas 2189-2218, 1935. . Onnophris. In: RE (primeira série), v. 18, tomo 1, colunas 483-484, 1939.

SCHARFF, Alexander. Die Ausbreitung des Osiriskultes in der Frühzeit und während des Alten Reiches. Munique: Bayerischen Akademie der Wissenschaften (Sitzungsberichte, Philos.-hist. Kl.), 1947.

SETHE, Kurt. Chenosiris. In: RE (primeira série), v. 3, tomo 2, coluna 2236, 1899.

Urgeschichte und älteste Religion der Ägypter. Leipzig: Deutsche Morgeländische Gesellschaft, 1930.

SILVERMAN, David P. (Ed.). Ancient Egypt. Nova York: Oxford University Press, 1997.

SINGER, Thomas C. Hieroglyphs, real characters, and the idea of natural language in English seventeenth-century thought. Journal of the History of Ideas, Filadélfia, v. 50, p. 49-70, 1989.

VANDIER, Jacques. La religion égyptienne. 2. ed. Paris: Presses Universitaires de France, 1949.

VELDE, Herman. Seth god of confusion: a study of his role in Egyptian mythology and religion. Reimpr. Leide: E. J. Brill, 1977.

WILKINSON, Richard H. Reading Egyptian art: a hieroglyphic guide to ancient Egyptian painting and sculpture. Londres: Thames and Hudson, 1994.

Symbol \& magic in Egyptian art. Londres: Thames and Hudson, 1999.

ARAÚJO, Emanuel. Plutarch and the allegoric reading of hieroglyphs. Classica, São Paulo, 11/12, p. 81-98, 1998/1999.

ABSTRACT: Up to the accurate translation of the hieroglyphs by Champollion in 1822, they were normarly interpreted as allegories. For Plutarch and many others authors, it was a kind of interpretatio graeca of Egypt. It is easy to notice it in the composition of Isis and Osiris, where it is possible to observe where the manipulation of that form of writing by means often wrong etymological interpretations examined here according to an egyptologist instrumental.

KEYWORDS: Plutarch; hieroglyphs; Isis and Osiris; Egyptian mythology. 